\title{
A Collaborative Research Process Studying Fruit Availability and Seed Dispersal within an Indigenous Community in the Middle Caqueta River Region, Colombian Amazon
}

\author{
$\underline{\text { Angela Parrado-Rosselli }}^{1,2,3}$
}

\begin{abstract}
The objective of this paper is to present a collaborative research process between the Nonuya indigenous community and western scientists whilst studying fruit production patterns and the role of animals in the spatial distribution patterns of terra firme rain forest tree species in the Colombian Amazon. The process is presented in four stages: initially with a distant relationship between western scientists and indigenous people, with little exchange of knowledge, which progressed into a collaborative research relationship involving a high exchange of knowledge. The first stage consisted of the indigenous people's participation an exclusively scientific research project on natural sciences, as passive fieldwork guides. The second stage occurred when the guide became a fieldwork assistant and received training and expertise in scientific methodologies for data collection. The relationship between western scientists and indigenous people developed into the ability to have frequent debates and discussions over observations, findings, and interpretations. In the third stage, the indigenous fieldwork assistant proposed his own research, wherein he combined both scientific methodologies, and dialogue with elders in order to obtain information. During the fourth stage of the process, high quality information, relevant to the needs of both the western scientists and indigenous people was generated. This collaborative research process allowed the exchange of experiences, methodologies, and learning, leading to a better understanding of tropical rainforests. In this paper, the implications of this experience for future studies with the indigenous communities are discussed.
\end{abstract}

Key Words: Amazon region; indigenous peoples'knowledge; Nonuya indigenous community; plant-animal relationships; scientific knowledge;Tropenbos-International Colombia.

\section{INTRODUCTION}

Seed dispersal plays an important role in determining range expansion and spatial and genetic structure of plant populations at local and landscape scales (Nathan and Muller-Landau 2000, Levin et al. 2003). It includes aspects such as patterns of fruit production, e.g., the number of seeds available in time and space, fruit removal by fruit eating animals, as well as the spatial patterns of seed, seedling, and sapling distribution relative to the parent trees. In tropical rainforests, particularly, seed dispersal by animals is crucial in the understanding of the regeneration dynamics of populations and communities, since most of the plants have fruits adapted for animal dispersal (Howe and Smallwood 1982, Nathan and Muller-Landau 2000, Terborgh et al. 2002).
Indigenous Amazonian communities' knowledge of plant-animal relationships is the basis for understanding and managing the natural resources in their territories from a symbolic perspective (Van der Hammen 1992, Reichel-Dolmatoff 1997). Cultural and every-day practices such as work, ritual dances, spiritual life, arts, health, and education are determined by symbolic associations between fruiting patterns of wild and/or cultivated plants and the behavior of some animal species, e.g., reproduction, movement between habitats, seed dispersal, or environmental features such as rainfall, i.e., the rain to ripe the wild grapes, the Chontaduro palm dry season, the wet season of fruits, the season of animal dance, and the season of the guan fruit tree (Van der Hammen 1992). Therefore, to maintain harmonious relationships between humans and the natural environment, Shamans must

\footnotetext{
${ }^{1}$ Institute of Biodiversity and Ecosystem Dynamics (IBED), Faculty of Sciences, University of Amsterdam, ${ }^{2}$ Tropenbos-International Colombia, Bogota, ${ }^{3}$ Faculty of Environment and Natural Resources, Universidad Distrital Francisco José de Caldas, Bogota
} 
negotiate with the spiritual owner of every season. Dances and rituals are also related to the fruiting season of particular cultivated or wild fruiting species, and their associated animals are organized in the roundhouse.

During the past decade, several studies have focused on the factors that influence the diversity and spatial distribution patterns of tree species in the Amazon rainforests (e.g., Pitman et al. 1999, Tuomisto et al. 2002, Duque 2004, Duque et al. 2003). Among these factors, it has been suggested that seed production patterns and seed dispersal by animals are of primary importance. However, these aspects are still poorly understood (Nathan and Muller-Landau 2000, Terborgh et al. 2002). Conservationists and scientists have suggested further studies on these topics as they may provide important information in the determination of minimum protected area sizes. In addition, they can help us understand the effect of human activity on tropical forests when balances and trade-offs between species are altered (Nathan and Muller-Landau 2000, Duque 2004, Laurance 2005, Peres 2005, Wright 2005).

Despite the fact that most of these investigations have been carried out on indigenous territories, only a few of them have included local, traditional/ indigenous ecological knowledge, participatory, or collaborative research methodologies that include the participation of local people as far more than just fieldwork guides. Moreover, the information obtained from such scientific research has not been interesting, useful, understood, and/or transmitted to the local people.

The objective of this paper is to present a collaborative research process between the Nonuya indigenous community and western scientists, whilst studying fruit availability and the role of animals in the spatial distribution patterns of terra firme rainforest tree species in the Colombian Amazon (Parrado-Rosselli 2005). First, the general framework in which this collaborative research was undertaken is described. The complete process of this interaction is then detailed, along with the information gathered throughout the process, the points they have in common, and the achievements that resulted. Finally, the implications of this experience, which can offer useful tools for future work with indigenous communities, are discussed.

\section{SETTING}

Following first contact with the western society some centuries ago, indigenous communities from the Amazon region have been subjected to many changes and pressures, which have affected their traditional models of natural resource management (Van der Hammen 1992, Reichel-Dolmatoff 1997). In the Colombian Amazon, as a result of the extractive economy, e.g., rubber exploitation, gold mining, fisheries, catholic missions, drug traffickers, and armed groups, indigenous people have been subjected to strong cultural and language losses, the desecration of sacred elements, i.e., petroleum, gold, and coca, and the disarticulation of clans and families. Thus, they have been in a permanent transformation and readaptation as the only survival mechanism both as individuals and cultures (Van der Hammen 1992).

During the last $30 \mathrm{yr}$, several institutions and organizations have worked in the Colombian Amazon, each aiming to research the sustainable use and conservation of this complex, biological, and culturally diverse region of the world. However, there has been a consistently arrogant attitude from western scientists toward the indigenous people's knowledge, having considered such knowledge systems as backward, inefficient, and inferior and founded on myth and ignorance in comparison to western scientific knowledge. Thus, several research projects have been proposed without having recognized or respected the knowledge of indigenous communities and their relationships with the environment. Moreover, indigenous people have felt that western scientists took advantage of their knowledge without rewards other than material goods (Rodríguez 2003). What has resulted is that indigenous people have become reluctant to share information and do not believe in western science.

\section{The Case of Tropenbos-International Colombia}

In the Middle and Lower Caquetá River region of the Colombian Amazon (Fig. 1), the experience of Tropenbos-International Colombia (TBC), in supporting research for conservation and wise use of tropical forests for over $18 \mathrm{yr}$, has shown that to generate useful information for an adequate understanding and management of biodiversity and natural resources, research should be developed not just from a scientific perspective, but also from a 
traditional/local perspective using participatory research mechanisms (Rodríguez and Van der Hammen 2002, Van der Hammen 2003). The initial cooperation between TBC and indigenous people of the area, or gente de centro as they call themselves based on the point of origin of Andoke, Uitoto, Muinane, and Nonuya people, was similar to current interactions between other research NGO's and local communities elsewhere in the tropics, where there is a reciprocal agreement for the supply of materials to the community in return for allowing and supporting research projects in their territories (Rodríguez and Van der Hammen 2002, Rodríguez 2003). Under the above scheme, several B.Sc., M. Sc., and Ph.D. research projects were completed without taking into account local interests and research needs; in other words "science for the sake of science" (Rodríguez 2003). During the past 10 yr, scientific research has developed into a combination of local actions, participatory research projects, and a generation of local initiatives (Rodríguez 2003) aimed at recovering and restoring the traditional knowledge that had been lost over the years. Several projects were proposed on topics such as management of sacred areas and natural resources, cultural principles of territorial management, annual cycles of nature, traditional knowledge, and productive projects (Rodríguez 2003). Undergraduate and postgraduate students have participated in these projects to help in their formulation, development of complementary projects, and the analysis of results (Rodríguez 2003). The research-accompaniment scheme has generated an interest in the restoration of indigenous values, and it has shown that western science may contribute to local information needs. Consequently, indigenous people have realized that not all scientific research carried out in their territories will be a negative experience. However, scientific research still exists that is not perceived as useful to the local communities, either because it does not appear to be relevant to local needs or because there is a weak knowledge dialogue between local inhabitants and western scientists.

\section{FRUIT AVAILABILITY AND SEED DISPERSAL: A NOTEWORTHY EXPERIENCE}

As a result of the successful relationship and cooperative experience between indigenous communities and the Tropenbos-International
Colombia (TBC), together with the $4 \mathrm{yr}$ of continuous fieldwork of the current author in this region of Colombian Amazon, a collaborative research project between western scientists and the Nonuya ethnic group began to form in 1999. It was part of a Ph.D. research thesis aimed at studying fruiting patterns and the role of animals in spatial distribution patterns of trees (Parrado-Rosselli 2005). The Nonuya people are settled in Peña Roja, a small village located at the western and eastern margin of the Caquetá River, in the Colombian Amazon (Fig. 1). This small community was severely reduced and pushed out of its original territories during the 1930s and 1940s by the violence during the rubber boom and the war with Peru in 1931. Today, the community consists of 10 households with approximately 120 inhabitants belonging to two Nonuya clans: the Mochilero, i.e., Oropendola clan and the Gavilán, i.e., Hawk clan. There are only four knowledgeable elders alive who regulate the management of health, society, and territory.

This collaborative research occurred from 1999 to 2002, and its process is presented in four stages (Fig. 2 ). Initially the research began by having indigenous people participating as passive guides. It then progressed such that indigenous people and western scientists worked together to incorporate both systems of knowledge to improve the understanding of plant animal relationships and to stimulate the recovery of traditional indigenous knowledge, which is rapidly being lost, particularly amongst youngsters. I describe the general aspects of this process based on examples from my personal experience and from the experience of Jairo Moreno, a young man from the Mochilero Nonuya clan who made the central contribution and made this collaborative research possible. Although Jairo Moreno could have been considered as a coauthor, I decided to assume the responsibility for the complete text as only I participated in the entire process of the investigation.

\section{Methodological considerations}

Scientific methodologies for studying fruit availability included monthly records of all the plants that produced ripe or unripe fruits above a height of $15 \mathrm{~m}$, i.e., trees, palms, lianas, vines, hemiepiphytes and epiphytes, located within eight $50 \mathrm{x}$ $50 \mathrm{~m}$ plots, which were established randomly along 
Fig. 1. Middle and Lower Caquetá River region, State of Amazonas, Colombia. (Map from: Duivenvoorden and Lips 1993). The Nonuya people are settled in Peña Roja, located at the western and eastern margin of the Caquetá River.

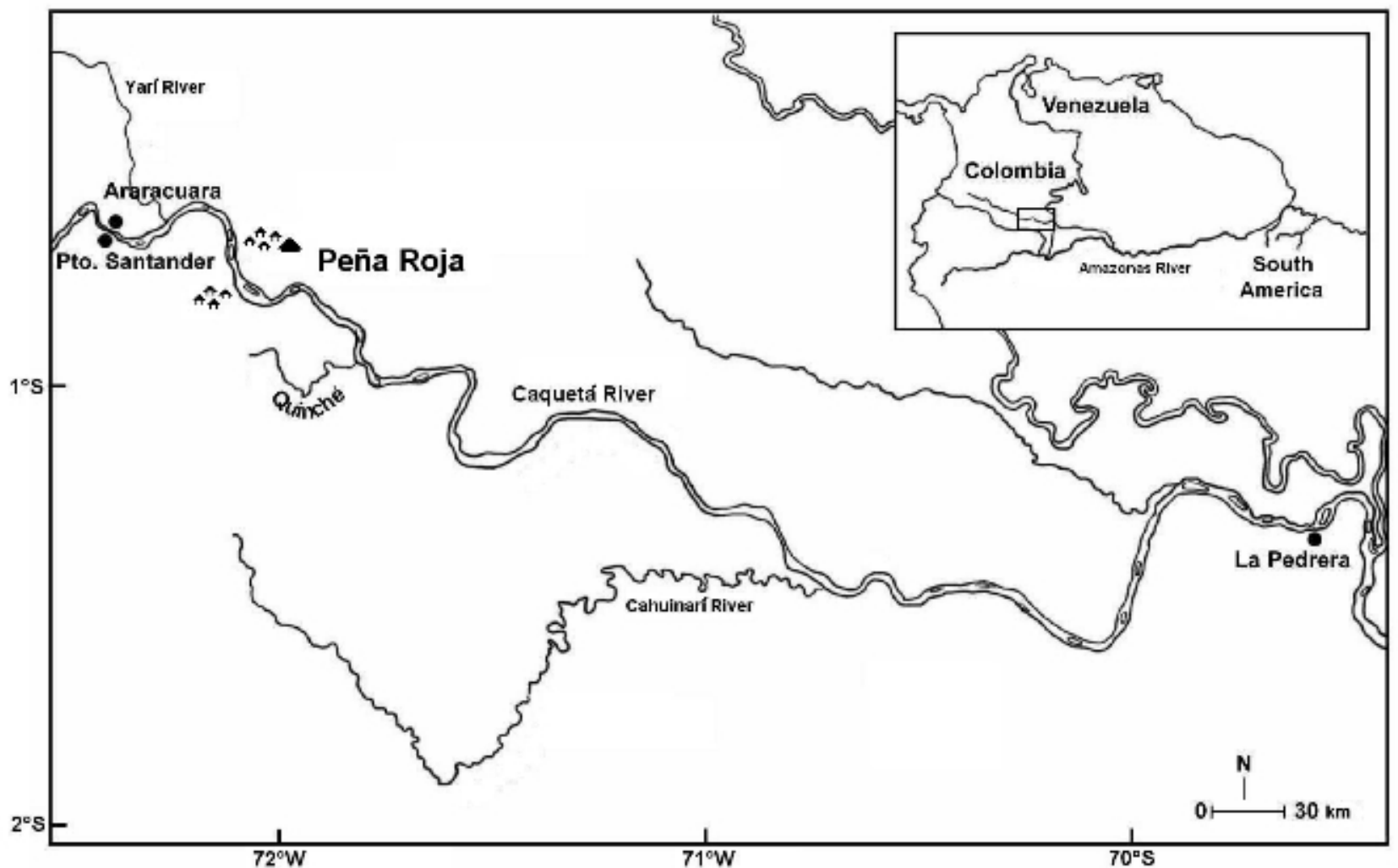

an existing trail system throughout a 95 ha area (Parrado-Rosselli 2005). Frugivory, seed dispersal, the spatial patterns of seeds, seedlings, and sapling distribution relative to parent trees of common animal-dispersed tree species, with regular, predictable and synchronous fruiting patterns were recorded, in order to evaluate the role of animals in the spatial distribution patterns of trees (ParradoRosselli 2005). On the other hand, opinions quoted from other people and qualitative information of the plant-animal relationships included in the text were obtained mainly by Jairo, through informal conversations and regular dialogue sessions with the four knowledgeable elders in the maloka, i.e., roundhouse. Although these techniques are not strictly comparable to systematic western methodologies of social work, we believe that the information obtained is of comparable rigor and reliability, particularly since most of them were held in the mambeadero, the ritual male place of the maloka, and the basic unit for the interaction with nature. The quotations cited come from those conversations that indigenous people have allowed to be recorded and documented. Finally, to elaborate this manuscript and its former drafts, Jairo and I undertook sessions in which we shared interpretations and discussed all of the information acquired. Some of his opinions given in quotes were extracted from the primary version given to Tropenbos-International Colombia (TBC) and the indigenous community. 
Fig. 2. Process for developing collaborative research between the Nonuya indigenous community and western scientists while studying fruit production patterns and the role of animals in the spatial distribution patterns of tree species. The starting point is a distant relationship between western scientists and indigenous people. From top to bottom the process consists on four main stages that indicate how this relationship with indigenous people, participating as passive guides, and little knowledge exchange developed into a collaborative-research relationship of high knowledge exchange. On the left side of the figure the sequence of knowledge gain. On the right side the increase of knowledge exchange.

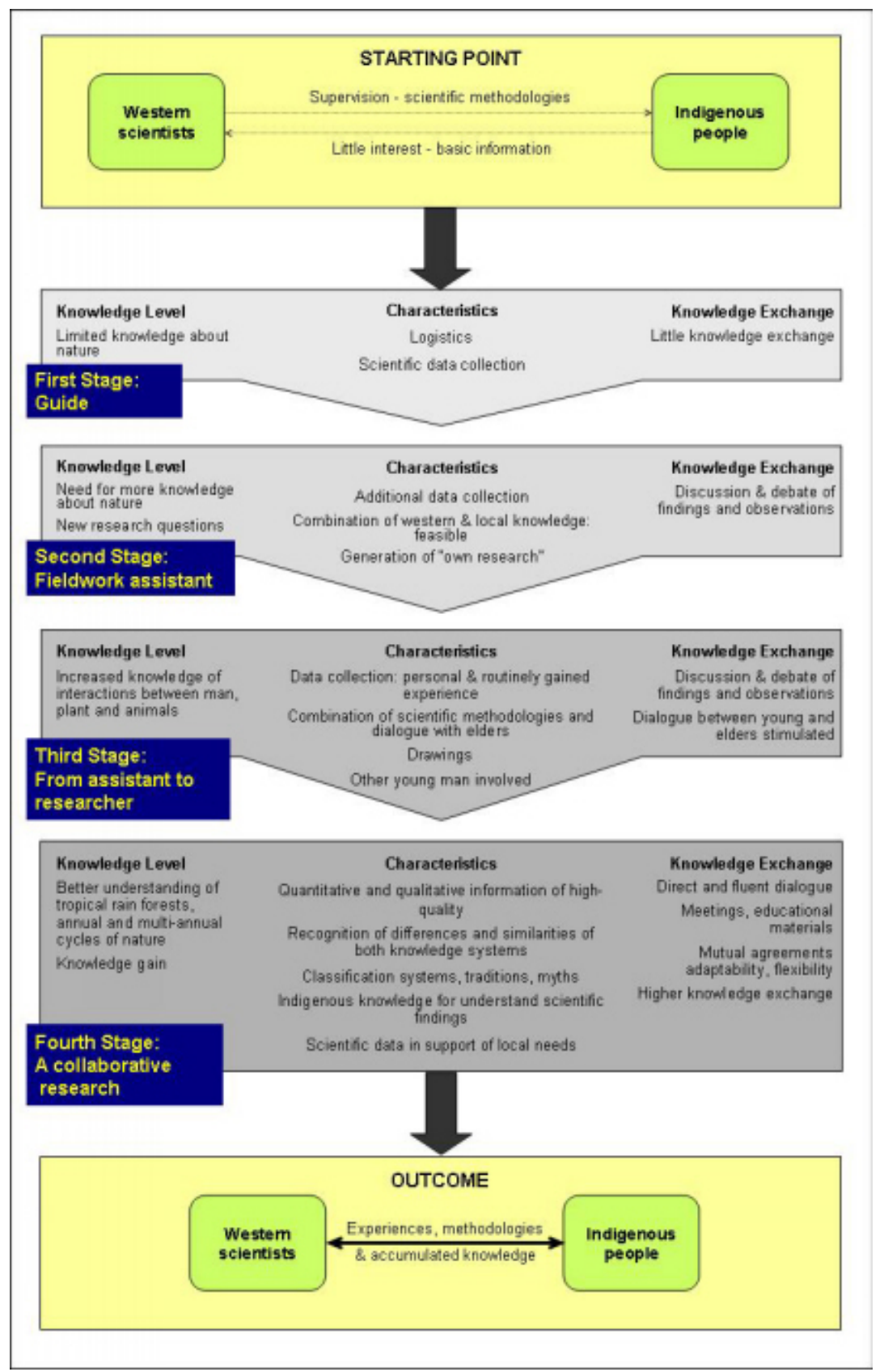




\section{First stage: the guide approach}

First, the Ph.D. thesis investigation was an exclusively scientific research on natural sciences. Indigenous people participated as guides, alternating between each other on a monthly basis. They helped in logistics and data collection under the direct supervision of the western scientist. This working scheme was based on the hierarchical employer-employee idea, wherein the western scientist provides training in the use of equipment and scientific methodologies for data collection; whilst indigenous people provided some basic information about the forest, fruiting trees, and animals. In general, most of the guides were young men who, according to the elders, had little interest in their own traditions and cultural knowledge, partly due to the superficial attractions of western society. The potential for knowledge exchange was therefore less than if older men had participated. Nowadays, in many sites of the Amazon region there are some participatory and collaborative research projects that are representations.

\section{Second stage: fieldwork assistant approach}

Here, similar to other research projects, I, the formal scientist hired one or two guides to help in the data recording. The guide, then, became a fieldwork assistant, receiving extra training and expertise in scientific methodologies for data collection. During the monthly censuses of fruit production patterns, several questions on the observations and data obtained arose during discussions between my students, the two indigenous fieldwork assistants, and me. For instance, how are the fruiting patterns of the cultivated and wild tree species most widely used by the indigenous people? How do patterns vary through time? Are these patterns different? What myths are there concerning the origin of trees? Do they have an ecological interpretation? Do ecological observations of these tree species have a mythological counterpart? How many fruits and seeds are produced by particular timber species? How do fruiting patterns and hunting sites associate, both from indigenous and western perspectives? Consequently, quantitative data obtained throughout scientific research had begun to generate questions that developed into frequent debates and discussions over observations, findings, and interpretations.

This dialogue illustrated the potential complementarity of western and indigenous people's knowledge. Although I was aware of the importance of including an indigenous perspective, a clear mechanism to integrate both knowledge systems was nonexistent. Thus, both scientists and indigenous fieldwork assistants realized that it was necessary to look for a working dynamic to stimulate dialogue and knowledge exchange. We were certain that this could result in better quality information, and would facilitate knowledge translation and dissemination. As a result, relevant research questions for both knowledge systems emerged, but most importantly, a process that enabled the recovery of traditional knowledge was a direct consequence of the nonindigenous persons participation:

... western research stimulated youngsters to become interested, to ask questions and to learn things about natural resource management, such as the origin of fishes, of animals, of cultivated fruiting plants, of trees and all those things (...) This has strengthened our local processes of transmission of knowledge (Hernán Moreno, maloka-owner Mochilero Nonuya Clan at Peña Roja, in the Middle Caquetá River region).

\section{Third stage: from fieldwork assistant to researcher}

Jairo Moreno, a young Nonuya man and son of the maloka-owner José Moreno, was particularly interested in learning about his own environment. As he believed that it was necessary to know more about nature, his territory, culture, and myths, he started to transform into a researcher. He could then propose his own research in order to solve some of the questions that emerged.

The loss of knowledge is currently generating disorder in the natural resources and causing nature to change. It is also the cause of several new and unknown diseases. Thus, to manage natural resources, it is important to know and learn about the seasons of the annual cycle; for example, the fruiting times, the seasons of the different animals species and how they are related to each other and to climatic aspects (...) It will allow humankind to organize its life, yet remaining forever respectful to nature (Jairo Moreno, young indigenous researcher, Mochilero Nonuya Clan at Peña Roja, in the Middle Caquetá River region). 
Fruit availability and relationships with the seed dispersers of the tree species most widely used by the Nonuya people was the research project proposed by Jairo Moreno. He proposed this topic based on the scientific Ph.D. thesis research that he was assessing and the questions that had emerged through it. Given that no schemes or protocols existed for the undertaking of a local indigenous investigation, methodologies and approaches emerged spontaneously through discussions, curiosity, and experience, and in accordance with research needs. Ultimately, both scientific methodologies and dialogue with elders were used to obtain information. Monthly phenological censuses of selected individuals from cultivated and wild fruiting tree species were used. The number of individuals and species bearing fruits each month, the number of fruits, and the amount of fruit mass/ mo was obtained. Data recording was included within his regular activities such as gathering, hunting, fishing, and planned or casual walks made along existent or new paths. He realized that data collection could be a personal routine experience.

\section{“...although it was necessary to spend some days in data collection (particularly for those that were western scientific), I could record a lot of information during my walks along the forest whilst on my way to or fish, or whilst looking for wood, lianas or fruits to eat" (Jairo Moreno).}

Regular dialogue sessions with the four knowledgeable elders were also held in the maloka, a traditional roundhouse, and with their authorization, some of the conversations were recorded and written down. During these meetings, qualitative information about fruit availability and plant-animal relationships were obtained, as well as myths of origin, classification systems, annual and multiannual cycles of nature, traditional aspects, and associated dances and rituals. In addition, meetings were held with the whole community to discuss the project, research questions, and research impacts and activities. Through these meetings, other members of the community were invited to join in on the research. From these meetings other young men became involved within the project through data collection, elaboration of drawings, and discussions.

The idea of this investigation was to make a contribution to the organizational plans of the Nonuya community at Peña Roja, aimed to develop our own research ideas,

\begin{abstract}
from which people would learn about their culture and traditions, but also receive training in the elaboration and execution of projects (Jairo Moreno).
\end{abstract}

Drawings were one of the most important ways to graphically depict the information and knowledge acquired. For indigenous people, knowledge is generally transmitted across generations by an oral tradition, whereas writing is relatively to new for them. As Spanish is not their first language, particularly amongst older people, conversations took place mainly in the indigenous language, and transcriptions in western characters became even more difficult and inaccurate. Thus, drawing was to indigenous people, as writing was to western scientists. In general, after the dialogue sessions with elders, drawings of animals, plants, or landscapes were made. They included a high level of detail and information, not only about the morphological and external characteristics of organisms (plants/animals), but also about their environmental, spatial, and temporal context (Fig. 3 ). The elaboration of drawings represented a challenge for the young people because it was a sign of how much they knew about the forest. This stimulated the search for knowledge, encouraging ever more questions to be asked of the elders, about characteristic features, stories, and myths related to given organisms. As further information was required, youngsters began to become more and more involved with the knowledgeable elders of the community. Consequently, elders were also interested in assessing the project and were enthusiastically expecting questions from the young people about their observations the forest.

One of the most important achievements of this research was that it brought elders and youngsters closer together, and that we realized the amount of knowledge that elders have (Jairo Moreno).

This transmission of knowledge involved training and preparation and had to be done by phases, gradually. It was carried out in the maloka, where the new apprentice-researcher was instructed by asking and listening at the primary level of his people's knowledge:

... if one wants to learn, he has thus, to prepare himself..., casabe has to be made, coca has to be made, ambil has to be made, that's it..., the one who wants to learn learns. Here, we are talking to you and others listen, in the moment that one listens, 
Fig. 3. Drawing of a Canangucho fruiting palm (Mauritia flexuosa) done by Jairo Moreno. According to indigenous people, drawings may include large amounts of information. For instance, in this case it indicates a particular place/forest type. This palm is generally found in patches locally known as Cananguchales, which are backswamps with poorly drained soils, and time of the year, i.e., June-July, canangucho fruiting season. Also, information on seed dispersal is provided: fruits consumed by "Danta de pintura negra," the Black Painted Tapir (Tapirus terrestris), as well as mythological associations. The cananguchales are sacred sites where animals meet on a particular time of the year.

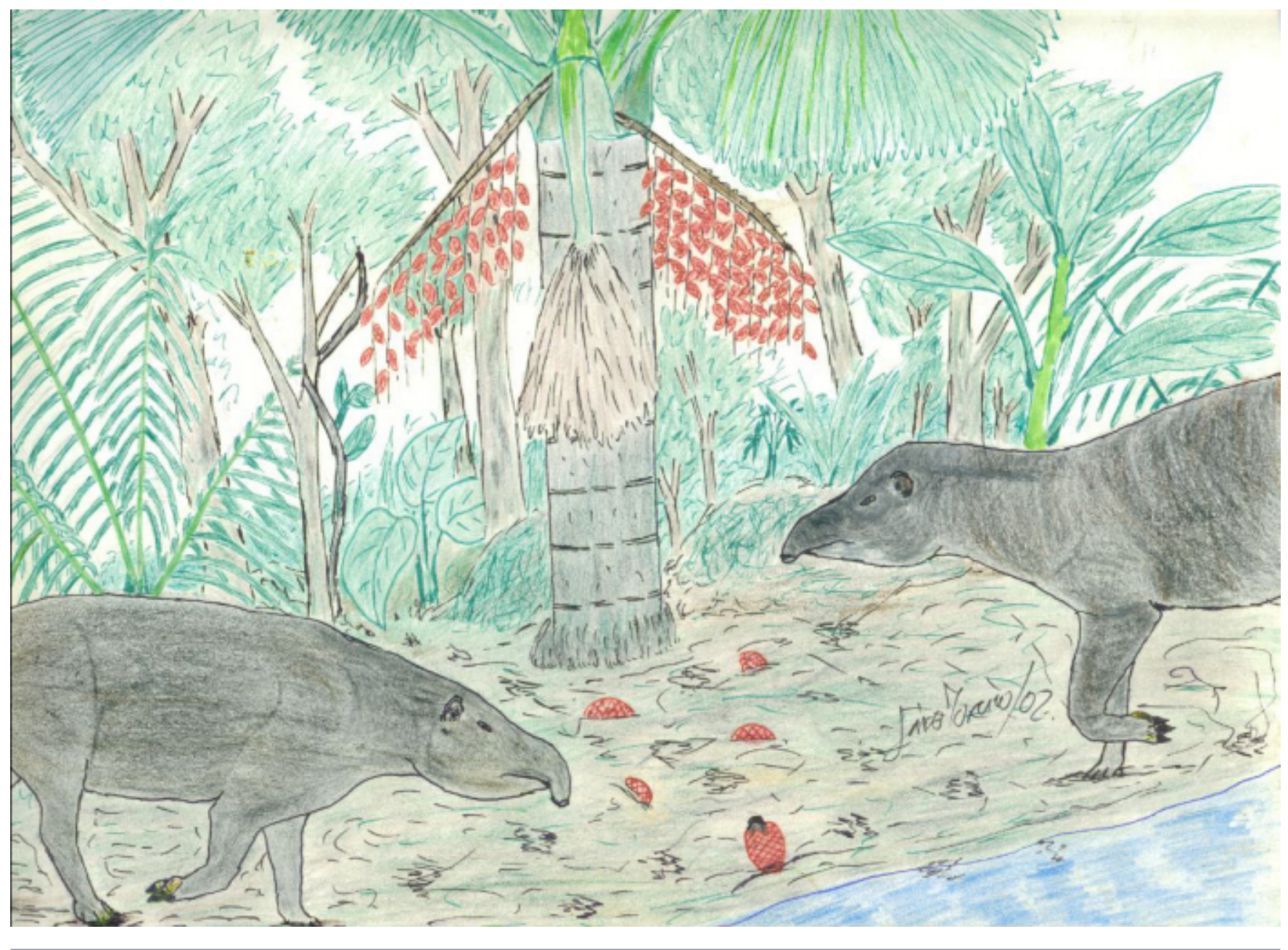

one learns, and the one that does not pay attention, screws it up! (...) That is why we learn and talk in the mambeadero (Abel Rodríguez, elder of the Gavilán Nonuya Clan at Peña Roja, in the Middle Caquetá River region).

As this process continued, the indigenous researcher was learning more and more about the interactions between humans, plants, and animals. Consequently, new and more relevant research questions emerged such as: What is the relation between the trees studied and their fruit consumers? Is there a special management of frugivores? What are the myths about the origin of the natural world? Can any of these myths explain our observations? 


\section{Fourth stage: collaborative research}

The consolidation of the indigenous young man as a researcher enabled the collection of high-quality information. From December 1999 to September 2002, 387 wild fruiting individuals in 166 species and 43 families bearing animal-dispersed fruits were recorded (see Parrado-Rosselli 2005). Eighty of these species were classified according to the Nonuya classification system. Additionally, monthly fruit production of the fruiting tree species and varieties most widely used by the Nonuya people were monitored from June 2000 to September 2002. According to the Nonuya classification system, they recognized 120 species, of which 42 were cultivated and 78 wild (Appendix 1). Nevertheless, according to the western scientific taxonomy, these corresponded to 80 species, whereas the other 40 were considered varieties. From these 80 species, 24 were cultivated and 56 were wild.

Despite these differences, both western scientists and indigenous people understood that although both systems of knowledge are based on observation experience, they are fundamentally distinct. Therefore, not everything should be translated, and/ or interpreted into the other's system; however, these must be taken into account and respected. Additionally, the myth of origin was obtained for each of the 120 species recognized by Nonuya people, and for the 16 groups of fruit-eating animals identified. From these animal groups, 35 species, according to the local/traditional Nonuya classification system, were birds and 50 were mammals (Appendix 2). Detailed drawings of all trees and animals studied were made.

This debate about classification systems led Jairo, and those who helped him, to learn more about their own classification systems, traditions, stories, and myths, which can be seen as the symbolic conceptualization of their interactions with the biotic and abiotic environment. Stories and myths are the basis for understanding and management of health, society, and territory. For example, through knowing and relating to the story of the origin and asking in the appropriate way, the Nonuya have the possibility of managing a plant or an animal for a specific end. Since not every indigenous person is a sophisticated possessor and user of arcane knowledge, most of these activities have been, and are still regulated by the knowledgeable elders. For the young ones, this is just the first step in the process of learning their traditional knowledge. In addition, although the story of the general origin has the same underlying theme, differences in individual stories were found between clans. In this particular case, in the Mochilero clan, Mooseji, the creator mother, brought all seeds from every wild plant; whereas, in the Gavilán clan, it is believed that some trees arose from the body of the creator elder Mookani:

He transformed his delights and happiness
into many cultivated trees. In contrast, he
translated all his aches, pains, and troubles
into trees, whose physiological features are
related or can cause the disease where they
come from. For example, Ajey+(Itching
tree; Endlicheria spp.; Lauraceae) comes
from the itching in his body; Fat+ba(Paca
tree Licaria guianensis - Lauraceae), from
the headache and a bitter taste in his mouth.
When he felt sticky he called all the lianas
and trees with milky latex, and when he felt
scented and dizzy he called them Gaanao
(Laurel tree of small leaves; Ocotea sp. -
Lauraceae).

In contrast, there were aspects in which one knowledge system provided useful information to the other or both systems. On the one hand, since indigenous knowledge is more concerned with qualitative information, quantitative scientific information about the number and kilograms of fruits and seeds produced/ha by different timber species such Lauraceae trees has been very useful for the design of productive projects and alternatives of resource management. This kind of information has also been obtained for nontimber forest products, such as lianas, particularly those associated with the elaboration of handicrafts and artifacts.

On the other hand, traditional knowledge complemented the results obtained throughout scientific research. In this particular research, the objective was to find out how seed dispersal by animals would predict the spatial distribution patterns of tree species with characteristics such as commonness, and regular and seasonal fruit production patterns (Parrado-Rosselli 2005). However, as I was focused on a particular tree species, it was difficult to extrapolate these results to other tree species. By means of interpreting and understanding indigenous myths of origin, it was possible to obtain additional information or formulating testable hypothesis on the effective 
seed dispersal agents of other tree species. For instance, in the origin of animals, one mythological hero, El abuelo de centro, transformed fruits and other foods into different game animals. He took a seed of a guama tree (Fat+gao) and threw it to the earth. When the seed fell, it transformed into an agouti. Consequently, El abuelo de centro called it "Paca of fruit of the black guama tree" (Fat+gaij+ fat+; Dasyprocta fuliginosa). Direct observations, thus, allowed Dasyprocta fuliginosa to corroborate as the principal and most effective seed dispersal agent of the guama tree (Fat+gaho; Parkia panurensis). Similar information was obtained for the "Tapir of white flower." (Nofaij+ t+e; Tapirus terrestris) originated from a combination of fruits, "small peccary that walks in herds" (Obajac+maije fafaim+; Pecari tajacu) originated from Miya juvehe (Poraqueiba sp.). This information was also useful to Jairo, since knowing the fruiting season of a plant species associated with a game animal allowed him to optimize his hunting activities through learning again where and when to hunt effectively. As he also learned to ask permission to the spiritual owners and to recognize that animals transformed from fruits were "true-animals," as well as being able to feed his family without fear of any dire consequences.

Furthermore, the combination of both knowledge systems provided tools for the interpretation of ecological observations and/or cultural beliefs or supported the other systems' conclusions. The next three examples illustrate this point. First, according to the origin of plants:

Once the creator elder, Mookani had created earth, Mooseji, the creator mother brought in her basket every seed from all wild plants: large trees, treelets, lianas, herbs, and spread them all over the earth. Mookani, then made the rain fall, and with the rainfall the seeds of the largest trees of the Earth sprouted. Aamehe trees (Buchenavia tetraphylla, Combretaceae) were amongst the earliest ones, and were the predecessors of all plants on earth. Not every seed spread by Mooseji sprouted at the same time. Each plant has a spiritual owner, who protects and manages the plant, and releases its seeds in a particular time.

From a western scientific perspective, this particular time for releasing the seeds symbolizes and refers to the fruiting seasons of the forest and each species, as most of them reproduce in a particular month and/ or in a given year. In addition, the rainfall sent by
Mookani, which made the seeds germinate, coincides with the wettest period of the year, i.e., April to June, when the fruiting peak of the forest occurs, and it is associated to appropriate climatic conditions for enhancing seed germination.

Second, there were important differences in the fruiting patterns between years: 2001 was a low production year, whereas 2000 and 2002 were both high production years. In tropical rain forests ecosystems, there is a strong tendency for high fruit production years to alternate with low fruit production years (Wright et al. 1999). According to indigenous people's knowledge the spiritual owner of each tree releases the seeds at a particular time but not necessarily every year. Therefore, there are actual fruiting years and false fruiting years.

Third, western scientific data showed that the terra firme rainforests of the Middle Caquetá River region exhibited buffering strategies during periods of low fruit availability (Parrado-Rosselli 2005). During periods of fruit scarcity in the forest, fruits in other ecosystems/plant-guilds such as those produced by cultivated fruiting trees became available. These peaked in the mid- and late-dry season after the fruiting peak of the forest, whereas troughs occurred in the wettest periods of the year when fruit production in the forest was very high (Fig. 4). From a scientific perspective, this is a strategy to enhance seed dispersal, as competition for seed dispersers is minimized and local movement of seed dispersers between habitats is stimulated. From the Nonuya perspective, cultivated fruiting trees have their wild equivalents. As said by El abuelo de centro, cultivating equivalents of wild fruiting trees maintains the reciprocity between man, plants, and animals. The fruiting peak of cultivated trees after the peak of the forest reduces fruit loss and damage of cultivated fruiting trees, as animals will be satiated, and consequently will not be attracted by the cultivated crop.

\section{LEARNING FROM EXPERIENCE: CONSIDERATIONS}

The process described in this paper has shown that collaborative research, in which indigenous people and western scientists work together to incorporate both systems of knowledge, has led to a better understanding of tropical rainforests. What in principle was simply a working dynamic within a 
Fig. 4. Fruiting patterns of cultivated trees and the forest obtained from June 2000 to September 2002 (Parrado-Rosselli 2005), in the Middle Caquetá River region. Mean monthly precipitation (1979-1990; Duivenvoorden and Lips 1993) is represented by a broken line.

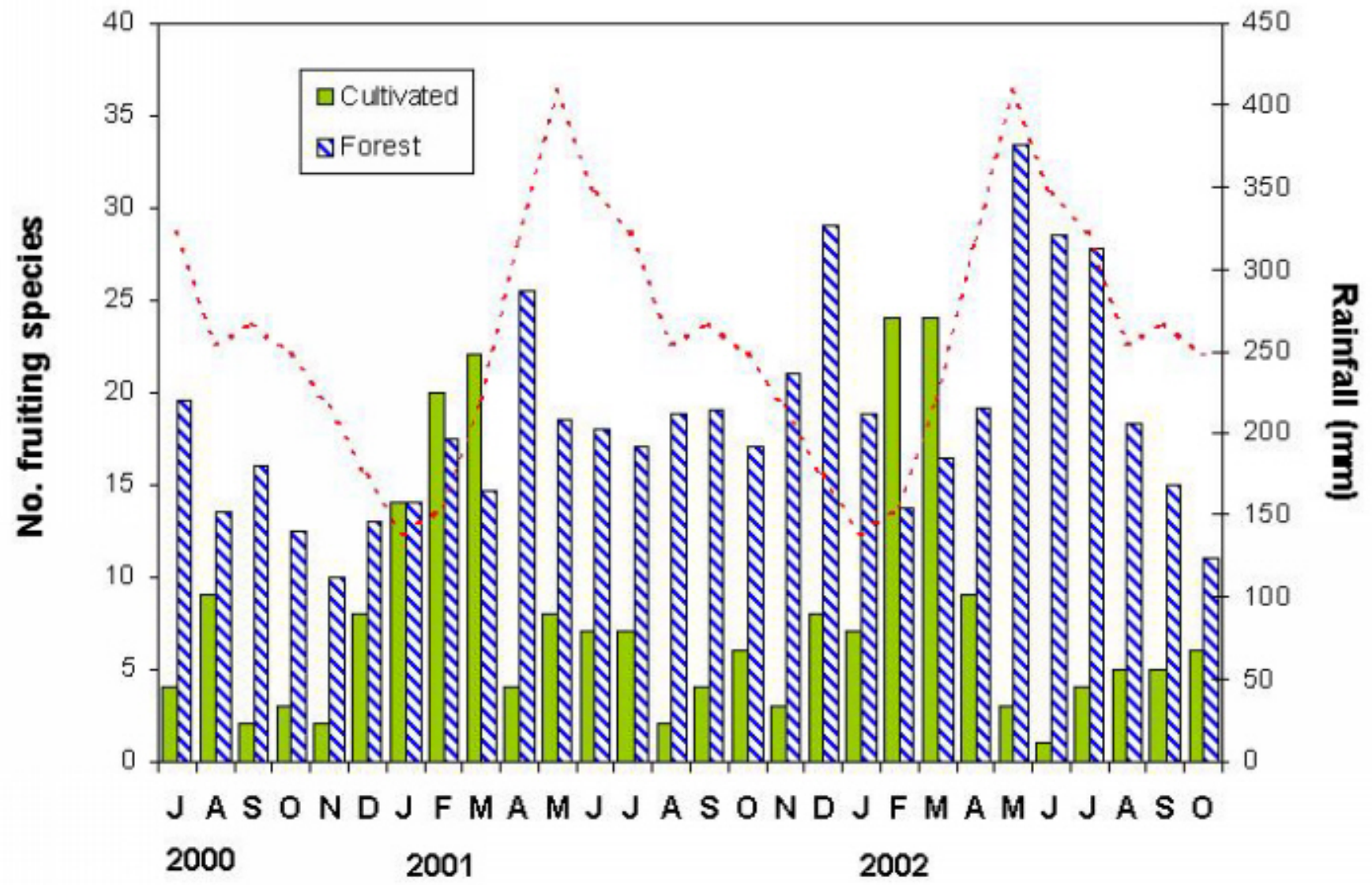

Months: Jul. 2000 - Oct. 2002

scientific research project resulted in a series of activities that have had a tremendous impact on the recuperation of traditional knowledge by young indigenous people, and has encouraged new relationships between western and indigenous people. Although success should not be determined by the products, but the quality of the process, this experience also allowed support to be given to the educational processes of the local school, e.g., an ethno-educational plan for the Pena Roja indigenous community, with educational materials, booklets, and posters. Moreover, the permanent participation of the different stakeholders allowed a permanent disclosure of all aspects of the process, methods, and results instead of only the results being shared.

In addition, due to the importance of seed dispersal by animals in regulating the composition and structure tropical rainforest ecosystems, and the importance of social mechanisms such as taboos and other regulations for resource conservation and sustainable resource use, the combination of both knowledge systems can provide basic and robust 
information for decision making and the design of participatory natural resource management strategies. For instance, plant-animal relationships looked upon from both knowledge perspectives could be useful in selecting ecological indicators on the status and condition of forests such as keystone species, structurally important species, flagship species, and umbrella species, amongst others. Nowadays, these indicators can be of particular help in the measurement of ecological integrity of protected areas and natural systems. Furthermore, annual cycles of fruiting plants may provide clues as to which animals interact with plants for food resources, and ecological indicators may elucidate the potential demographic consequences of variation in fruit production, and may define changes of the activities of indigenous people, e.g., hunting, fishing, gathering, cultivation, according to changes in the environment.

This collaborative research exercise has offered an enriching experience to both indigenous and western participants. They have realized that it was possible to carry out scientific projects and research combined with a local approach.

... there was a different social atmosphere within the community. People were thinking about so many things that are worth doing; a fundamental theme was the integration of all these community and educational activities around the ecological calendar (Hernán Moreno, maloka-owner)

Therefore, the combination of traditional ecological knowledge and western science should be promoted, scrutinized, questioned, and applied in those instances in which it could make a difference in the quality of research, the effectiveness of management, and the involvement of resource users in decisions that affect them (Huntington 2000). This kind of exercise is the basis of future participatory research strategies dealing with local concerns and investigative needs.

Ultimately, indigenous people, in this case, recognized that they are an essential part of nature and have a responsibility toward the natural world. They have recovered the management of facets that previously played a fundamental role in their culture. A strong cultural capacity building can be achieved when projects have a profound cultural basis, as well as the self-management of their projects proving to be an excellent exercise of autonomy. These and other experiences with Tropenbos-International Colombia in the Colombian Amazon have become a very important tool in the effective negotiation with armed groups (Rodríguez 2003). This collaborative research has encouraged indigenous people and formal scientists to include similar schemes within follow-up strategies and scientific initiatives, and will certainly continue as a valued component in future conservation-related research projects. New programs and sustainable conservation strategies, including this kind of research, can be designed in order to address the rapidly changing social, economic, and biophysical environment occurring in Amazonian indigenous territories.

Responses to this article can be read online at: http://www.ecologyandsociety.org/voll2/iss2/art39/responses/

\section{Acknowledgments:}

This paper was possible thanks Jairo Moreno, a member of the Indigenous community Peña Roja. After long conversations and joint work while I was carrying out field work, he made this collaborative research possible and being able to combine both knowledge systems brilliantly. I am especially grateful to Carlos A. Rodríguez, director of Tropenbos-Colombia, who guided Jairo and me during the whole process of this research including the elaboration of this manuscript. I am also grateful with the Nonuya indigenous community for their support, friendship and all those lessons about life, nature and conservation. My deepest gratitude to Frans van Dunné for his help in the elaboration of figure 2, and for his criticism and suggestions for improving the manuscript. Paula Ungar, Antoine Cleef, Dan Yeloff and two anonymous reviewers who revised earlier versions of the manuscript. Dan Yeloff and Gloria Rosselli revised the English for with I am also grateful. This research was supported by Tropenbos-International, and the UNESCO Fellowships Programme in support of Priority Programme Areas (2004-2005). 


\section{LITERATURE CITED}

Duivenvoorden, J. F., and J. M. Lips. 1993. Ecología del paisaje del Medio Caquetá. Memoria explicativa de los mapas. Estudios en la Amazonía colombiana. III A-III B. Tropenbos-Colombia, Bogotá, Colombia.

Duque, A. 2004. Plant diversity scaled by growth forms along spatial and environmental gradients: a study in the rain forests of northwest Amazonia. Dissertation. University of Amsterdam, Tropenbos Ph.D. Series 1, Tropenbos-International, Wageningen, The Netherlands. Available online at: http://www. http://www. www.tropenbos.org/files/colduque.htm

Duque, A., J. Cavelier, and A. Posada. 2003. Strategies of tree occupation at the local scale in terra firme forests in the Colombian Amazon. Biotropica 35:20-27.

Howe, H. F., and J. Smallwood. 1982. Ecology of seed dispersal. Annual Review of Ecology and Systematics 13:201-228.

Huntington, H. P. 2000. Using traditional ecological knowledge in science: methods and applications. Ecological Applications 10:1270-1274.

Laurance, W. F. 2005. When bigger is better: the need for Amazonian mega-reserves. Trends in Ecology and Evolution 20:645-648.

Levin, S. A., H. C. Muller-Landau, R. Nathan, and J. Chavé. 2003. The ecology and evolution of seed dispersal: a theoretical perspective. Annual Review of Ecology, Evolution and Systematics 34:575-604.

Nathan, R., and H. C. Muller-Landau. 2000. Spatial patterns of seed dispersal, their determinants and consequences for recruitment. Trends and Ecology and Evolution 15:278-285.

Parrado-Rosselli, A. 2005. Fruit availability and seed dispersal in terra firme rain forests of Colombian Amazonia. Dissertation. University of Amsterdam, Tropenbos Ph.D. Series 2, TropenbosInternational, Wageningen, The Netherlands. Available online at: http://www. http://www.tropen bos.org/files/Colparrado.htm

Peres, C. A. 2005. Why we need megareserves in Amazonia. Conservation Biology 19:728-733.
Pitman, N. C., J. T. Terborgh, M. R. Silman, and P. Nuñez-Vargas. 1999. Tree species distributions in an upper Amazonian forest. Ecology 80:2651-2661.

Reichel-Dolmatoff, G. 1997. Chamanes de la selva pluvial: ensayos sobre los indios Tukano del Noroeste Amazónico. Themis Books, London, UK.

Rodríguez, C. A. 2003. Proyectos-plata o proyectos-pensamiento. Las iniciativas propias en el Medio Río Caquetá. Pages 1-17 in M. V. Rivera, editor. Alternativas productivas en la Amazonia colombiana: enfoques y procesos desde lo local. COAMA, Bogotá, Colombia.

Rodríguez, C. A., and M. C. Van der Hammen. 2002. Participation: stakeholders and the information they need. Pages 1-3 in A. Lawrence and B. Ambrose-Oji, editors. Participatory assessment, monitoring and evaluation of biodiversity (PAMEB). Environmental Change Institute, University of Oxford, Oxford, UK. Available online at: http://www.etfrn.org/etfrn/wor kshop/biodiversity/documents/theme4intro.pdf

Terborgh, J. T., N. Pitman, M. Silman, H. Schichter, and P. Núñez. 2002. Maintenance of tree diversity in Tropical forests. Pages 1-17 in D. J. Levey, W. R. Silva, and M. Galetti, editors. Seed dispersal and frugivory: ecology, evolution and conservation. CABI International, Wallingford, UK.

Tuomisto, H., K. Ruokolainen, A. D. Poulsen, R. Moran, C. Quintana, G. Caas, and J. Celis. 2002. Distribution and diversity of pteridophytes and Melastomataceae along edaphic gradients in Yasuní National Park, Ecuadorian Amazonia. Biotropica 34:516-533.

Van der Hammen, M. C. 1992. El manejo del mundo. Naturaleza y sociedad entre los Yukuna de la Amazonía colombiana. Estudios en la Amazonía colombiana. IV. Tropenbos-Colombia, Bogotá, Colombia.

Wright, S. J. 2005. Tropical forests in a changing environment. Trends in Ecology and Evolution 20:553-560.

Wright, S. J, C. Carrasco, O. Calderón, and S. Paton. 1999. The El Niño Southern Oscillation, variable fruit production, and famine in a tropical forest. Ecology 80:1632-1647. 
APPENDIX 1. Cultivated and wild fruiting trees most widely used by the Nonuya indigenous community, in the Colombian Amazon. Name in Muinane, local name in Spanish, scientific name and fruiting month. 
APPENDIX 2. Most common fruit eating animals studied from the local/traditional Nonuya perspective in the Colombian Amazon. The species are presented according to the local/traditional classification system. Since several animal species could not be translated or classified into the western scientific taxonomy, scientific names were assigned only for the general groups. Local names in Spanish are also given. 